\title{
Evolution of the Clavier Functions in the Orchestra
}

\author{
Malofeeva Inna \\ Russian State Specialized Academy of Arts \\ Moscow, Russia \\ e-mail: inna_edel@mail.ru
}

\begin{abstract}
The article contains a brief review of symphony orchestra forming in the XVII-XVIII centuries and considers a role of the stringed keyboard instruments in it. The changing of the functions of these instruments in the orchestra of the $19^{\text {th }}$ century and some Romanticism elements of piano introduction into the orchestra as a coloring instrument are analyzed.
\end{abstract}

Keywords-Baroque orchestra; symphonic orchestra; stringed keyboard instruments; harpsichord; piano functions

\section{INTRODUCTION}

The grand piano is the king of instruments! According to $\mathrm{S}$. Feinberg, it is «a kind of microcosm in comparison to the vast horizons of modern music universe». It is difficult to overestimate the importance of the piano for the world music culture. Thanks to its musical advantages such as versatility, a great potential and a wide spectrum of expressive means the piano remains in demand, causing a great interest from composers, music scientists, performers and listeners.

There are a lot of studies about piano music; however the piano as an orchestral instrument still stays scantily explored phenomenon and much work in this area remains to be done. The present article contains a brief review of the «orchestral» piano history and gives some examples of its usage.

We should point out that in different historical periods there were many variants of interrelations between the stringed keyboard instruments and other instruments of the orchestra. Some of them was quite stable, others may be reckoned among the interjacent or experimental forms. We would like to emphasize that this relationship lacks determined transitions from one form to another, since its development was not linear and there's no clear line of succession.

\section{ADMISSION OF STRINGED KEYBOARD INSTRUMENTS INTO THE ORCHESTRA}

Initially the piano entered the orchestra as a substitute to the harpsichord. Therefore, we better start from a brief survey of the Baroque orchestra forming and the harpsichord's role in it.

A number of the authors believe that the orchestra's history began in the 16th century. Its birth coincided with secular instrumental music crystallization and the transition from the polyphonic style to the homophony.

Originally, the instrumentation of the orchestral works was defined by two important factors: the availability of instruments and availability of instrumentalists to the composer. However later, when opportunities of a wider presentation of the orchestra music appeared, composers began to orchestrate their pieces for the standardized orchestra, which could be found at any big musical centre. The evolution of the orchestra was closely related to the improvement in instrument making and to the professional advancement of the instrumentalists who performed in orchestras.

The harpsichord was one of the most important participants in chamber and orchestral music, thanks to its specific bright sound, tempered tuning and an ability to perform a polyphonic texture. He structured all the musical works in terms of intonation, harmony and metro-rhythmic organization. This is what N. Harnoncourt writes about it in his book «Baroque Music Today: Music as Speech, Ways to a New Understanding of Music»: "The harpsichord was a soul of the Baroque orchestra. Not only it helped in the rhythmic organization of musicians, who played without a conductor, but also as a basso continuo instrument provided harmonic development of the composition with the help of the chords and additional voices»).

One of the first examples of the usage of harpsichord in the orchestra we find in Monteverdi's Orfeo, where the composer marks the structure of the performers: «fifteen violas of different sizes, two violins, four flutes, two hautbois, two cornets, four tubas, five trombones, a harp, two harpsichords, three little organs»».

A famous musicologist A. Kars estimated the roles of the stringed keyboard instruments in the orchestra of that period even higher. He says, «a lute, akin to it theorbo and archlute or chitarrone together with a harpsichord, a spinet and an organ create the basis of the primitive orchestras, which accompanied the vocal parties of the first operas and oratorios, beginning from 1600. Particularly in that time a figured bass, or basso continuo was invented. (italics supplied) [7].

From the end of the 16th century up to the time of appearance of Haydn`s, Mozart's and Beethoven`s mature works basso continuo as an essential structural and identifying element was so typical for the epoch in question and so widespread that, according to Kars, it could be called a «basso continuo period». In this period, stringed keyboard instruments were obligatory in the orchestra.

So, the first established relationships between stringed keyboard instruments and orchestra were formed in the 
symphonic compositions, written in the basso continuo technique. Here the stringed keyboard instruments usually filled out the texture and were generally used for harmonic support and metro-rhythmic organization. As it has already been marked, the first pianos, which entered to the structure of the orchestra in the second half of the 18th century, at first inherited those harpsichord's functions.

\section{PURPOSE AND ROLE OF CLAVIER}

One more genre very interesting from the perspective of the stringed keyboard instruments usage in the symphony orchestra is a clavier concert. During the period of harpsichord domination and the growth in popularity of the piano (end of the 18th - beginning of 19th centuries) a clavierist had to play along with the orchestra in tutti, improvising figured bass.

Famous researchers Eva and Paul Badura-Skoda in their book «Interpreting Mozart on the Keyboard» mark that «Nowadays we no longer doubt that in performing his piano concertos Mozart at times used the piano as a continuo instrument. Time and again, in tutti sections, he scrupulously wrote out the bass part in the piano, or marked it 'col basso' on every page» [2].

Thus in these concerts the clavier had two roles: on one hand it was a solo instrument, on the other - an orchestral instrument, increasing the orchestra tutti.

The steadiness and the longevity of this tradition shows the following facts: in three Mozart's piano concerts - F-dur (K. 413), A-dur (K. 414) and C-dur (K. 415), which were published in 1785 by Artaria, - the clavier part contains a carefully figured bass. In the autograph of Es-dur concert (K.271), we can see equally detailed figured bass. At the same time, there are clear «tasto solo» markings in some sections, where the piano bass line should be played on its own, without any chords. Usually it's more quiet, «chamber» fragments or unison episodes.

In the clavier concerts figured bass realization appeared to be a very sustainable practice. Even the first edition of Ludwig van Beethoven's Piano and Orchestra Concert N 1 (1801) contains figured bass [2]. Hence, the tradition of the pianist playing together with the orchestra in tutti existed up to the end of the 18th century.

After the decline of the basso continuo and improvisation technics, the ways of the clavier and the symphony orchestra separated. The piano left the orchestra. For some time their relationship was limited to the concert genre. Still at the beginning of the 19th century the composers started to include improved piano in the orchestra, but the role of the stringed keyboard instruments' at that time drastically changed [7].

\section{IV. "COLORISING INSTRUMENT OF THE SYMPHONY ORCHESTRA”. EXEMPLIFIED BY “LÉLIO” OF BERLIOZ}

American researcher James Rauscher in his thesis «Treatment of the piano in the orchestral works of Igor Stravinsky» asserts that in Romanticism period the grand piano as a colorizing instrument was initially included into structure of the symphony orchestra by Hector Berlioz in his «Lélio, ou le retour à la vie», H 55 (1831), synthetic monodrama for the narrator, a choir and an orchestra [10]. This composition is a kind of sequel to the famous Symphonie fantastique.

For us the greatest interest represents musical piece number six - Fantasy on Shakespeare's "The Tempest". In spite of the fact that the composer marks, "a chorus, an orchestra and a four-hand piano», the piano here stands as an orchestral instrument.

H. Berlioz himself gave very impressive description of the fragment with piano part: «Whole choruses of the Spirits of the Air flung capriciously athwart the orchestra, speaking to fair Miranda in melodic, harmonious strains, the sweetest language fraught with poetry, then casting threats in boisterous accents at the awkward brute Caliban. And the voices of my sylphs shall be carried on light clouds of harmony, aglow and brilliant with the magic splendor of their dazzling wings...» [3]. Thanks to the great instrumentation in fact Berlioz uses upper register of the piano, flutes, clarinets and violins - we have a sensation of unearthly lightness, chatoyant glistening light. The piano is used from the first to the fourth octave. During many pages in the first part we could hear trills of different highs and in the second - rising arpeggios, which is answered by the downward arpeggios of the flutes and clarinets. In this Fantasy such texture remains the basic.

In the middle of the first episode at the same scale the piano has a tremolo, which is performed piano. Tremolo is typical for the orchestra string instruments and, in this case, it represents a classical example of the symphony interpretation of the piano. As a result, here comes into existence a mirror effect: the piano in the orchestra / the orchestra in the piano. To be more precise, the piano as an orchestral instrument (piano in the orchestra) imitates an orchestra sounding (orchestra in the piano).

The episode finishes with the rising passage in first and second piano parts both with the woodwind instruments (flute, flute piccolo, clarinets). Here the piano once again has the coloring function, but its combination with other orchestral instruments is unique. This is the first example of duplication.

Much later, in the tempest scene (two bars before 29), we find another version of using the piano. Here the whole orchestra (including grand piano) performs massive chords forte. In this case, the piano has not only colorizing, but also texture thickening role.

Then in the piano's part once more appears tremolo, but now it sounds fortissimo and covers a much wider scale: from the first to the fourth octave including. The grand piano functions are the same as in the previous two bars.

Thus, by adding the piano to the structure of the orchestra in his monodrama «Lélio», Berlioz becomes an innovator in using of the piano as an orchestral instrument. Of course, in this monodrama the main piano's function is colorizing in different combinations with other instruments (roll call, dubbing, overlay). Also in the same piece it has another role: the texture thickening. 


\section{PIANO WITH ORCHESTRA IN GLINKA'S “RUSLAN AND LUDMILA"}

The second chronological example of the piano usage in the orchestra we find with M. Glinka, in his opera «Ruslan and Ludmila» (1842). We should mark that in the $19^{\text {th }}$ century Russian composers' symphonic works fortepiano as an orchestral instrument had completely different functions in comparison with the Western examples.

In opera Ruslan and Ludmila the grand piano appears in the introduction and it is connected to the Bayan`s image. The piano imitates the sound of the gusli, performing together with the harp arpeggiated chords. Here Glinka introduces to the listener the piano's new function - imitational, or illustrative. In the next part of the Bayan's song there's another version of interaction of the vocal party with the piano party. The piano a kind of replies to the Bayan's phrases. Thanks to the dialogic structure of this episode and more developed imitative texture, characteristic for the piano, the grand piano gets to the same level as the tenor soloist, adding to his expressions.

Bayan's second song reminds a romance very much, where the harp and the piano accompany the soloist. The bowed string instruments play only the syncopes and some supporting voices. Thanks to such an innovative method, this episode keeps some unusual characteristics of timbre and texture, which as if separate it from the main action. «Bayan as if leaves the stage and addresses an audience without theatrical rhetoric, with no orchestral cothurni [6].

In the final the fortepiano's timbre appears almost simultaneously with Ruslan, who comes to the sleeping Ludmila with a magic ring. At first, the grand piano function comes to nothing more than harmonic support in the traditional for the romances of that period manner «bass+chord» with melodic supporting voices. Then fortepiano disappears for a short time, but seemingly just in order to appear again with the typical for the piano, more developed and rich texture. It is symbolic that the piano arpeggio becomes illustration of some sort of the author's remark «Light clouds slowly appear on stage», which may be considered a sign of transition from the fairy tale to reality. There piano as orchestral instrument has two functions at the same time: illustrative and dramaturgic.

The piano passages and the figurations interlace with richly ornamented vocal line (Ludmila's part). This remind us of the dialogic episode from the first Bayan song. The grand piano appears from time to time as accompanying instrument and plays «bass + chord» texture, thickening the light sound of the string instruments, playing pizzicato, and the brief harp chords. Virtuosic piano arpeggio, covering four upper octaves, and the broken octaves in bass help to create the sensation of a bright and joyful apotheosis of the whole opera.

Grand piano part finishes with three tonic chords, which, actually, make a point in the development of the plot. K. Zenkin remarks: "in the Glinka's "Ruslan" spectacular passages and final chords in B-flat major marks the end of a fairytale. As the composer himself says, «it was a fairytale and this is an ending» [6]. The episodes with the piano usage frame the main action, creating direct associations with the literary basis: Pushkin's «Ruslan and Ludmila» poem also framed by author's narration (in introduction and epilogue). Including the piano into the orchestra score of the opera, Glinka not only got the desired colorization, but also solved a number of compositional objectives, providing a philosophic depth to the whole action.

\section{CONCLUSION}

Thus, appearing in the orchestra as successor of the harpsichord - a basso continuo instrument — the grand piano began to play an entirely different role. For Baroque composers the most important thing was creation of polyphonic and tonally stable texture as a foundation for their symphonic works. However, later the situation has changed, and the piano's unique colorization abilities got to the foreground. The earliest example of using the piano as the coloristic orchestra instrument we find in H. Berlioz`s Lelio monodrama. In Russian music the first appearance of the piano in the orchestra structure was connected to the synthetic genre of the opera, where the grand piano particularly plays an imitational or illustrative role.

\section{REFERENCES}

[1] Harnoncourt N. Baroque Music Today: Music as Speech, Ways to a New Understanding of Music.

[2] Badura-Skoda E.P. Interpreting Mozart on the Keyboard. Moscow, Music, 1972.

[3] Berlioz H. «Lélio, ou le retour à la vie», H 55.

[4] Berlioz H. Instrumentation great tract.

[5] Wikipedia -the free encyclopaedia.

[6] Zenkin K. Glinka's Ruslan and Liudmila as a unique phenomenon of the Russian opera stage.

[7] Kars A.K. The History of Orchestration. Translated from English. Moscow, Music, 1989.

[8] Feinberg S.E. Pianism as an Art. - Moscow, Music, 1969.

[9] Conductors Guild. Book Review - Beethoven Concerto No. 1 in C Major, Op. 15 (Bärenreiter Urtext) by prof. Jon Ceander Mitchell, 2013.

[10] International Music Score Library Project, 2006-2014.

[11] Rauscher James F., B.M.E., M.M. Treatment of the piano in the orchestral works of Igor Stravinsky: a dissertation in fine arts, 1991. 